\title{
Assessing physician and patient acceptance of infliximab biosimilars in rheumatoid arthritis, ankylosing spondyloarthritis and psoriatic arthritis across Germany
}

\author{
This article was published in the following Dove Press journal: \\ Patient Preference and Adherence \\ 13 March 2017 \\ Number of times this article has been viewed
}

John Waller'

Emma Sullivan'

James Piercy'

Christopher M Black ${ }^{2}$

Sumesh Kachroo

'Adelphi Real World, Manchester, UK; ${ }^{2}$ Center for Observational and Real-

World Evidence (CORE), Merck \&

Co., Inc., Kenilworth, NJ, USA
Correspondence: Sumesh Kachroo Merck \& Co., Inc., 126 East Lincoln Avenue, Rahway, NJ 07065, USA Tel +l 7325943847

Email sumesh.kachroo@merck.com
Objectives: We examined rheumatologists' motivation for prescribing biosimilars, assessed their treatment preferences in relation to prescribing behavior and explored patient attitudes to biosimilars.

Methods: Data were taken from the Adelphi Real World Biosimilars Programme, a real-world, cross-sectional study undertaken with German rheumatologists and patients with rheumatoid arthritis, ankylosing spondyloarthritis or psoriatic arthritis in 2015-2016. Rheumatologists provided data on their prescribing behavior and attitudes toward biosimilars and invited the next eight eligible consecutive consulting patients to complete a questionnaire. Rheumatologists were split into "investigative", "conservative" and "other" groups.

Results: Overall, 50 rheumatologists and 261 patients participated. Biosimilars accounted for $<10 \%$ of all biologic therapy prescriptions, and $>95 \%$ of rheumatologists would prescribe a biooriginator rather than biosimilar as the first- or second-line therapy if unrestricted. Patients showed some reluctance to accept biosimilars, and a small proportion of patients were unhappy when switched from a biooriginator to a biosimilar. Satisfaction with treatment was highest in patients who started treatment with a biooriginator prior to biosimilar availability. Patient concerns when starting treatment with a biooriginator or a biosimilar included not knowing enough about the drug (25\%-41\%), potential side effects $(26 \%-32 \%)$ and potential long-term problems (19\%-30\%).

Conclusion: Study results demonstrate that there is some reluctance from patients to accept biosimilars and the need to educate patients who are unsure to allow them to be involved in decision making, highlighting the importance of patient and physician communication. There remains a need for further research into nonclinical switching and the long-term impact of prescribing biosimilars.

Keywords: biosimilars, rheumatology, autoimmune, patient acceptance, physician acceptance

\section{Introduction}

The World Health Organization defines biosimilars as "biotherapeutic products [...] similar in terms of quality, safety and efficacy to an already licensed reference biotherapeutic product". For generic drugs, demonstration of identical structure and bioequivalence to the reference product is required for licensing purposes; however, biotherapeutic products (biologics) are larger and more complex entities, and this approach is not considered appropriate for biosimilars. ${ }^{1}$ A biosimilar must therefore be developed strictly in accordance with procedures used for the reference product 
(or biooriginator) to ensure that no clinically meaningful differences exist between the "quality, safety and efficacy" and the "safety, purity and potency" of the two. ${ }^{2,3}$

In 2013, the European Medicines Agency's (EMA) Committee for Medicinal Products for Human Use (CHMP) approved the marketing of two infliximab biosimilar compounds for the same indications as the biooriginator. ${ }^{4}$ While Europe has historically been supportive of biosimilar products, this was the first example of a biosimilar monoclonal antibody being approved and provided a defining moment for the use of biosimilars in a highly regulated market. ${ }^{4}$ Both products were launched in major European markets, including Germany, in February 2015.,6 Germany has seen some of the highest market shares in the European biosimilars market, with $\sim 50 \%$ volume uptake reported. ${ }^{7}$ Automatic substitution of biooriginators with biosimilars by pharmacists is not allowed in Germany (this is mandated for generics); however, recommended prescribing quotas have been set, although targets vary across regions. ${ }^{8-11}$

There has been a paucity of published evidence regarding the impact of the launch of biosimilars on physician prescribing, but it would appear that, despite a high level of acceptance from a regulatory standpoint, there is still a marked reluctance from physicians to prescribe biosimilars. ${ }^{12,13}$ Before prescribing a biosimilar, a physician would require reassurance that it has the same activity and safety profile as the biooriginator and that the quality of the production process is guaranteed - regulatory requirements in both Europe ${ }^{2}$ and the USA ${ }^{3}$ ensure this, but concerns apparently remain. ${ }^{14}$

In one study using an online survey of European physicians across a range of disciplines, lack of a complete and accurate understanding of biosimilars, and the differences between generics and biosimilars, was identified, which might be one factor in the low acceptance levels by physicians. ${ }^{15}$ In a discrete choice experiment, Hungarian gastroenterologists showed some reluctance to prescribe biosimilars rather than biooriginators in inflammatory bowel disease, although this was less marked in patients who were biologic naive. ${ }^{16,17}$ In another online survey in Europe, Brazil, Japan and China, rheumatologists with $\leq 10$ years of practicing experience were less likely to prescribe, or more doubtful about prescribing, biosimilars than those with longer experience. ${ }^{18}$ Less experienced rheumatologists stated that treatment guidelines and a lack of local data were key reasons for not prescribing biosimilars; these were not cited as reasons for nonprescribing by those with $>20$ years' practice experience. ${ }^{18}$ Despite prescription quotas, it has been reported that only a quarter of rheumatologists in Germany feel under pressure from health care authorities to switch patients to biosimilar therapies and that less than a third were aware that approval of the two licensed infliximab biosimilars was for all indications approved for the biooriginator. ${ }^{19}$

As the active involvement of patients in treatment decisions is advocated, the attitudes of patients to biosimilars are also important; however, little is available in the literature on this topic. ${ }^{20-22}$ One of the few related publications reports an online survey in Europe and the USA showing only $6 \%$ of the general population with even a general impression of biosimilars, although significantly higher awareness (20\%-30\%) in patients diagnosed with a disease for which one or more biologic therapy is available and who are members of a patient advocacy group. ${ }^{23}$

A biosimilar for etanercept was approved by CHMP in January 2016, and approval of further biosimilars, a number of which will be treatment options in rheumatoid arthritis (RA), is extremely likely over the next months and years. ${ }^{24}$ Biosimilars for adalimumab, certolizumab pegol, golimumab, ustekinumab and rituximab are in development. ${ }^{25-28}$ To ensure optimum uptake of available products, it will be essential to have an in-depth understanding of physicians' and patients' perspectives with regard to biosimilars. In particular, it will be important to understand where nonclinical factors are playing a part, something which is clearly lacking in the literature.

This study was undertaken to begin to address the lack of evidence in this evolving field, by examining what motivates prescribing of infliximab biosimilars by rheumatologists, to assess whether rheumatologist preferences match actual prescribing behavior, to explore rheumatology patient acceptance of biosimilars and to understand patient satisfaction and concerns and how these relate to treatment with biooriginators and biosimilars.

\section{Methods}

Data were drawn from the Adelphi Real World Biosimilars Programme (2015/2016), a real-world, cross-sectional study based on the completion of detailed record forms by physicians and a self-completion questionnaire by patients (Supplementary materials). The study was undertaken between December 2015 and March 2016 with rheumatologists across Germany. The methodology was based on that used in the Adelphi Real World Disease Specific Programmes, which has been published previously. ${ }^{29}$

\section{Study population and data collection}

Rheumatologists were identified from public lists, and those meeting the eligibility criteria were invited to participate in the program. Key eligibility criteria were as follows: qualified 
in rheumatology between 2 and 35 years; actively involved in the management of patients with RA, ankylosing spondyloarthritis ( $\mathrm{AxSpA})$ and psoriatic arthritis (PsA) and managing at least one patient with each disease in each of the following patient groups (Figure S1):

- BioSN: patient receiving infliximab biosimilar who was previously biologic naive

- BioSE: patient receiving infliximab biosimilar who has experience of a biooriginator

- BioOA: patient receiving infliximab biooriginator, initiated after February 2015

- BioOB: patient receiving infliximab biooriginator, initiated before January 2015

Participating rheumatologists provided data on their prescribing behavior and attitudes toward biosimilars via a 30 -min online survey. They also recruited the next eight consecutive consulting patients aged $\geq 18$ years, with a formal physician-confirmed diagnosis of RA, AxSpA or PsA and being treated with either a biooriginator or a biosimilar. The quota for the study dictated that twice the number of patients being treated with a biosimilar was recruited than those being treated with a biooriginator. Each patient was invited to complete an online patient self-complete form, containing detailed questions on demographics, current conditions, level of satisfaction with current treatment and perspectives and opinions on using biologic therapies, including biosimilars and biooriginators.

\section{Analysis}

Rheumatologists were asked to indicate the relative importance to them of a number of factors when making prescribing decisions. Physicians allocated 100 points across prespecified factors in response to the question "When making prescribing decisions which factors are most important to you?" At analysis, factors relating to similar themes were combined into the following three groups:

1. Investigative: primarily concerned with symptom improvement and disease modification (prespecified factors = "reduction of symptoms", "disease modification", "impact on quality of life")

2. Conservative: primarily concerned with safety (prespecified factors $=$ "safety")

3. Other: influenced primarily by other factors (prespecified factors = "extent of scientific evidence", "budgetary impact", "out of pocked cost to patient", "ease of prescribing", "likelihood of patient compliance" and "patient acceptability/comfort")

Physicians were allocated to one of the three groups based on the sum of points they allocated to the factors in the group. If a physician's allocation of points was higher than the sample mean for a certain group, they were assigned to that group; if their allocation of points was higher than the sample mean for more than one group, they were assigned to the group for which they allocated most points.

Based on their prior experience of biooriginators and biosimilars, patients were split into the four groups indicated previously for analysis. Patients currently receiving biooriginators were classified depending on whether they were prescribed the BioOB or BioOA; a biosimilar alternative was available, as it was considered that this might affect a patient's attitude toward their medication.

Specific objectives of the analysis were as follows:

1. To highlight the prescribing behaviors of rheumatologists who already prescribe biosimilars, to explore the factors that motivate them to do so and to investigate whether these factors differ between rheumatologists with different prescribing patterns

2. To explore whether rheumatologists encounter difficulties in convincing patients to accept biosimilars and whether this differs between patients who were offered a biosimilar when biologic naive, those who were switched from a biooriginator to a biosimilar when a switch was indicated for clinical reasons and those who were switched from a biooriginator to a biosimilar for nonclinical reasons

3. To assess patient understanding of, and satisfaction and concerns with, biologic treatment and how these differ between those switched to a biosimilar from a biooriginator, those receiving a biosimilar who are biologic naive and those who remain on a biooriginator

Descriptive statistics presented are as follows: for numeric variables, the mean and standard deviation; for categorical variables, the number and percentage of subjects in each category.

\section{Ethics}

Patients provided informed consent via a tick box on the front of the patient self-completion questionnaire. The data were collected according to market research guidelines; hence, no source validation was possible or required. ${ }^{30}$ Patient and doctor identities were not known to the analysis team. No identifiers were recorded for the patients; patient and physician forms for the same "matched" patients were linked by unique numeric codes preprinted on the questionnaires. The study performed in accordance with the European Pharmaceutical Marketing Research Association (EphMRA) guidelines and the US Health Insurance Portability and Accountability Act 1996. 


\section{Results}

A total of 50 rheumatologists participated in this study, with 23 rheumatologists assigned to the "investigative" analysis group, 17 rheumatologists assigned to the "conservative" group and 10 rheumatologists assigned to the "other" group. Patient self-completion questionnaires were completed by 261 patients (133 RA, 65 PsA and 63 AxSpA), with 88, 86, 40 and 47 patients in the BioSN, BioSE, BioOA and BioOB groups, respectively.

\section{Prescribing behaviors}

Biosimilars made up $<10 \%$ of the biologic therapies and $<4 \%$ of all drugs that rheumatologists prescribed for the three conditions under study (Table 1). There was an expectation by the participating rheumatologists that this would increase over the following 12 months, with the greatest proportion of future biosimilar prescribing anticipated for patients with AxSpA (Table 1). When asked about their preferences for prescribing under the assumption of unrestricted circumstances (ie, no prescribing guidelines or other restrictions), $>95 \%$ of rheumatologists indicated that they would prefer to prescribe a biooriginator to a biosimilar as either the first-line therapy or the second-line therapy; this decreased to $80 \%-92 \%$ when considering the third-line therapy (Figure 1).

When asked their reasons for prescribing biosimilars instead of biooriginators, $86 \%$ of investigative rheumatologists indicated that a desire to get experience with the new product(s) was a reason and $64 \%$ of them indicated that a belief that efficacy is equivalent to the biooriginator was a reason (Figure 2A). A desire to get experience with the new product(s) and a belief that efficacy is equivalent to the biooriginator were indicated as reasons for prescribing biosimilars instead of biooriginators by $65 \%$ of conservative rheumatologists and $50 \%$ of those in the other group (Figure 2A). Only 64\% of investigative rheumatologists

Table I Rheumatologist-stated prescribing of biosimilars currently and expected in 12 months

\begin{tabular}{|c|c|c|c|c|c|c|}
\hline & \multicolumn{3}{|c|}{$\begin{array}{l}\text { Currently } \\
\text { prescribing }\end{array}$} & \multicolumn{3}{|c|}{$\begin{array}{l}\text { Expect to be } \\
\text { prescribing in } \\
12 \text { months }\end{array}$} \\
\hline & RA & AxSpa & PsA & RA & AxSpa & PsA \\
\hline $\mathrm{N}$ & 49 & 49 & 48 & 50 & 50 & 50 \\
\hline $\begin{array}{l}\text { Percentage of total } \\
\text { prescribed drugs }\end{array}$ & 2.7 & 3.3 & 3.0 & 4.1 & 5.1 & 4.0 \\
\hline $\begin{array}{l}\text { Percentage of total } \\
\text { prescribed biologic therapies }\end{array}$ & 7.9 & 9.1 & 9.0 & 12.4 & 14.7 & 12.2 \\
\hline
\end{tabular}

Note: $\mathrm{N}$, number of rheumatologists responding.

Abbreviations: AxSpa, ankylosing spondyloarthritis; PsA, psoriatic arthritis; RA, rheumatoid arthritis.

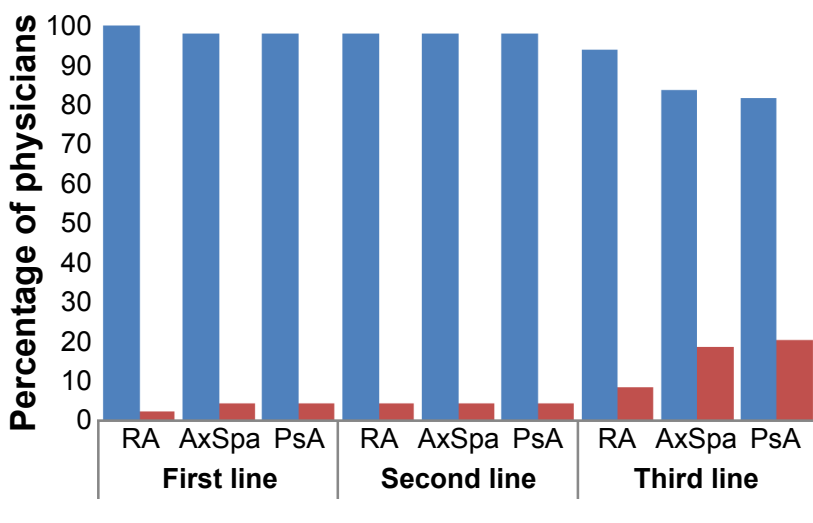

Biooriginator Biosimilar

Figure I Rheumatologist prescribing preference when it is assumed that there are no restrictions or guidelines.

Abbreviations: AxSpa, ankylosing spondyloarthritis; PsA, psoriatic arthritis; RA, rheumatoid arthritis.

selected the lower cost of the biosimilar as a reason for prescribing a biosimilar rather than the biooriginator, compared to $71 \%$ of conservative rheumatologists and $88 \%$ of those in the other group (Figure 2A).

In providing as many responses as they wished to the question "Once biosimilars are more widely available, how do you expect to use them?", the response selected by the highest proportion (47\%) of investigative rheumatologists was "When a treatment change is required, I will select the biosimilar version of a molecule I would otherwise have prescribed"; this was selected by $37 \%$ of conservative rheumatologists and only $16 \%$ of those in the other group (Figure $2 \mathrm{~B}$ ).

When a treatment change is required, I will select a biosimilar of a different molecule rather than the branded molecule I would otherwise have prescribed

was selected by $47 \%$ of conservative rheumatologists, $33 \%$ of investigative rheumatologists and $20 \%$ of those in the other group (Figure 2B).

\section{Patient attitudes}

The mean percentage of patients in the BioSN group (never previously prescribed a biooriginator or a biosimilar) reported by rheumatologists to accept a biosimilar without reluctance was $70 \%$, compared to $56 \%$ of patients currently receiving a biooriginator and with no clinical reason for a change in therapy (Table 2). A small proportion of patients would not accept treatment with a biosimilar but would accept the biooriginator; the mean values across rheumatologists were $7.3 \%$ of biologic-naive patients and $18.5 \%$ of those currently treated with a biooriginator and with no clinical indication for a therapy change (Table 2). Rheumatologists reported 

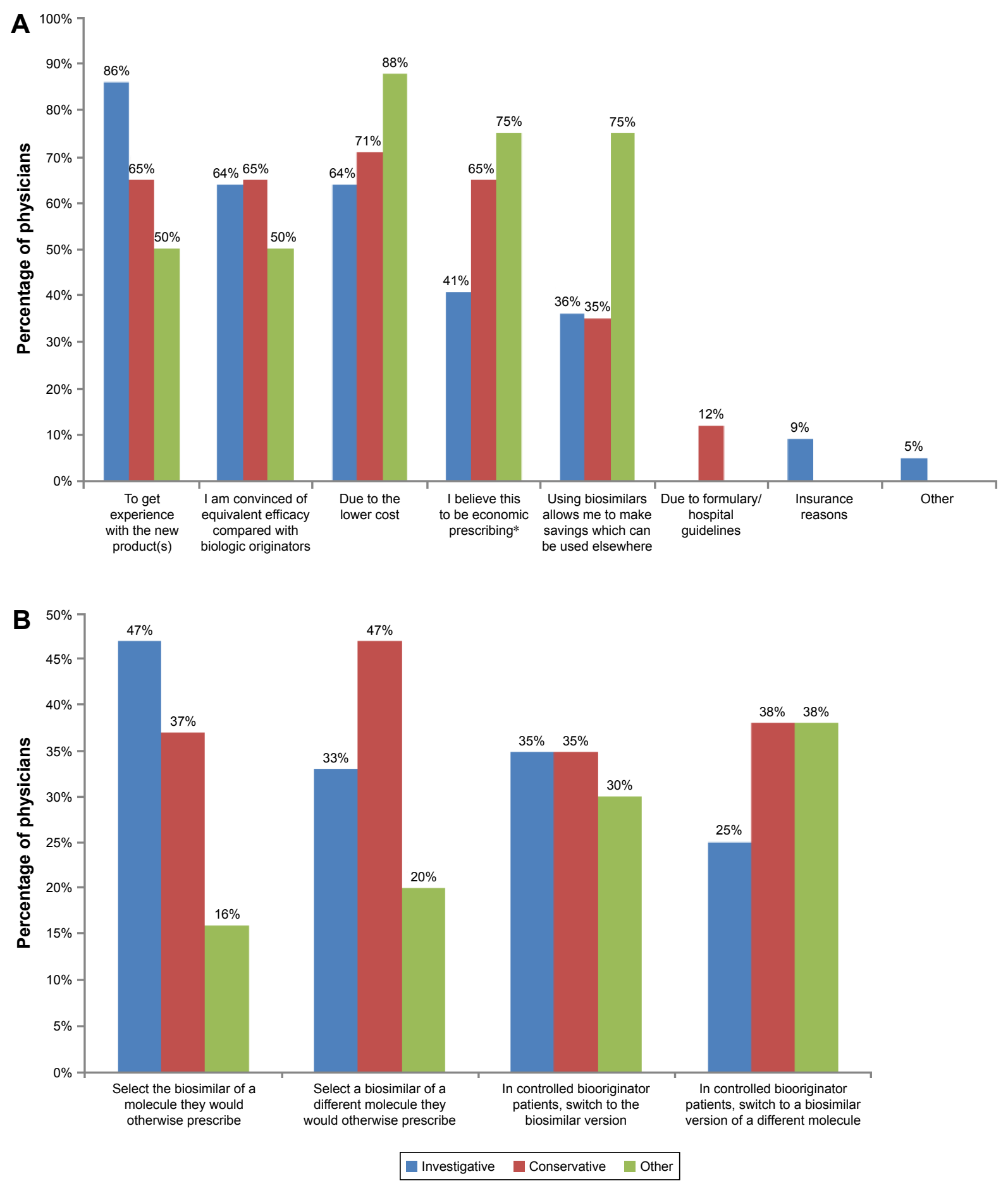

Figure 2 Rheumatologists' prescribing behaviors.

Notes: (A) Reasons switched patients receiving biooriginators to patients receiving biosimilars. (B) Intended prescribing of biosimilars when more widely available. *Compared to the prescription of a biooriginator.

that a small proportion (mean $\sim 5 \%$ ) of patients refused any form of biologic therapy, regardless of the patient's prior experience with biologic therapy or the reason for a switch in therapy (Table 2).

The majority of patients being changed from a biooriginator to a biosimilar were indifferent to the change (Figure 3).
A slightly higher proportion of patients with no clinical reason for the change indicated some degree of unhappiness compared with those being switched for clinical reasons, and a numerically greater proportion of patients who were somewhat happy with the change were being changed for clinical reasons (Figure 3). 
Table 2 Patient acceptance of biosimilars

\begin{tabular}{cccc}
\hline $\begin{array}{l}\text { Patient } \\
\text { status }\end{array}$ & $\begin{array}{c}\text { Biologic } \\
\text { naive }\end{array}$ & $\begin{array}{l}\text { Biooriginator } \\
\text { patients in need } \\
\text { of switch for clinical } \\
\text { reasons }\end{array}$ & $\begin{array}{l}\text { Biooriginator } \\
\text { patients not in need } \\
\text { of switch for clinical } \\
\text { reasons }\end{array}$ \\
\hline $\begin{array}{r}\text { Patients accepted without reluctance (\%) } \\
\text { N }\end{array}$ & 48 & 48 & 48 \\
Mean & 71.2 & 61.3 & 56.3 \\
SD & 28.46 & 28.94 & 34.88 \\
Patients reluctant but accepted as no other choice (\%) & \\
N & 48 & 48 & 48 \\
Mean & 16.1 & 23.5 & 19.6 \\
SD & 17.88 & 20.31 & 19.14 \\
Patients refused but accepted biooriginator (\%) & \\
N & 48 & 48 & 48 \\
Mean & 7.3 & 10.8 & 18.5 \\
SD & 10.74 & 13.14 & 24.43 \\
Patients refused biosimilar and biooriginator (\%) & \\
$\mathrm{N}$ & 48 & 48 & 48 \\
Mean & 5.4 & 4.4 & 5.6 \\
SD & 7.42 & 6.33 & 8.29 \\
\hline
\end{tabular}

Note: $\mathrm{N}$, number of rheumatologists responding.

Abbreviation: SD, standard deviation.

\section{Patient understanding, concerns and satisfaction}

The majority of patients were satisfied with the current treatment of their condition (Figure 4A). Patients who had been receiving a biooriginator since before biosimilars were introduced (BioOB group) appeared to be more satisfied than those in other groups, with $38 \%$ of this group being very satisfied (Figure $4 \mathrm{~A}$ ), compared to $27 \%, 30 \%$ and $22 \%$ in the BioSN, BioSE and BioOA groups, respectively.

When patients were asked what concerns they had when they were first prescribed their current treatment, the concern most commonly indicated was that they did not know enough about the drug; $36 \%-41 \%$ of patients prescribed a biosimilar selected this option compared to $25 \%-30 \%$ of patients prescribed a biooriginator (Figure 4B). Few patients expressed a concern that there were better medications available or that they were being given a cheaper and less effective medication, although this was more of a concern for patients prescribed a biosimilar who had previously received a biooriginator than those from the other patient groups (Figure 4B). Concern about potential side effects was expressed by $26 \%-32 \%$ of patients, with the highest proportions indicating this as a concern being those groups receiving biooriginators (Figure $4 \mathrm{~B}$ ). The proportion of patient concerned that their medication was too expensive was similar (17\%-19\%) between the group of previously biologic-naive patients prescribed a biosimilar and both groups prescribed a biooriginator; it was somewhat lower $(10 \%)$ in those prescribed a biosimilar who had previously received a biooriginator (Figure 4B). However, 14\% of biologic-naive patients prescribed a biosimilar felt they were

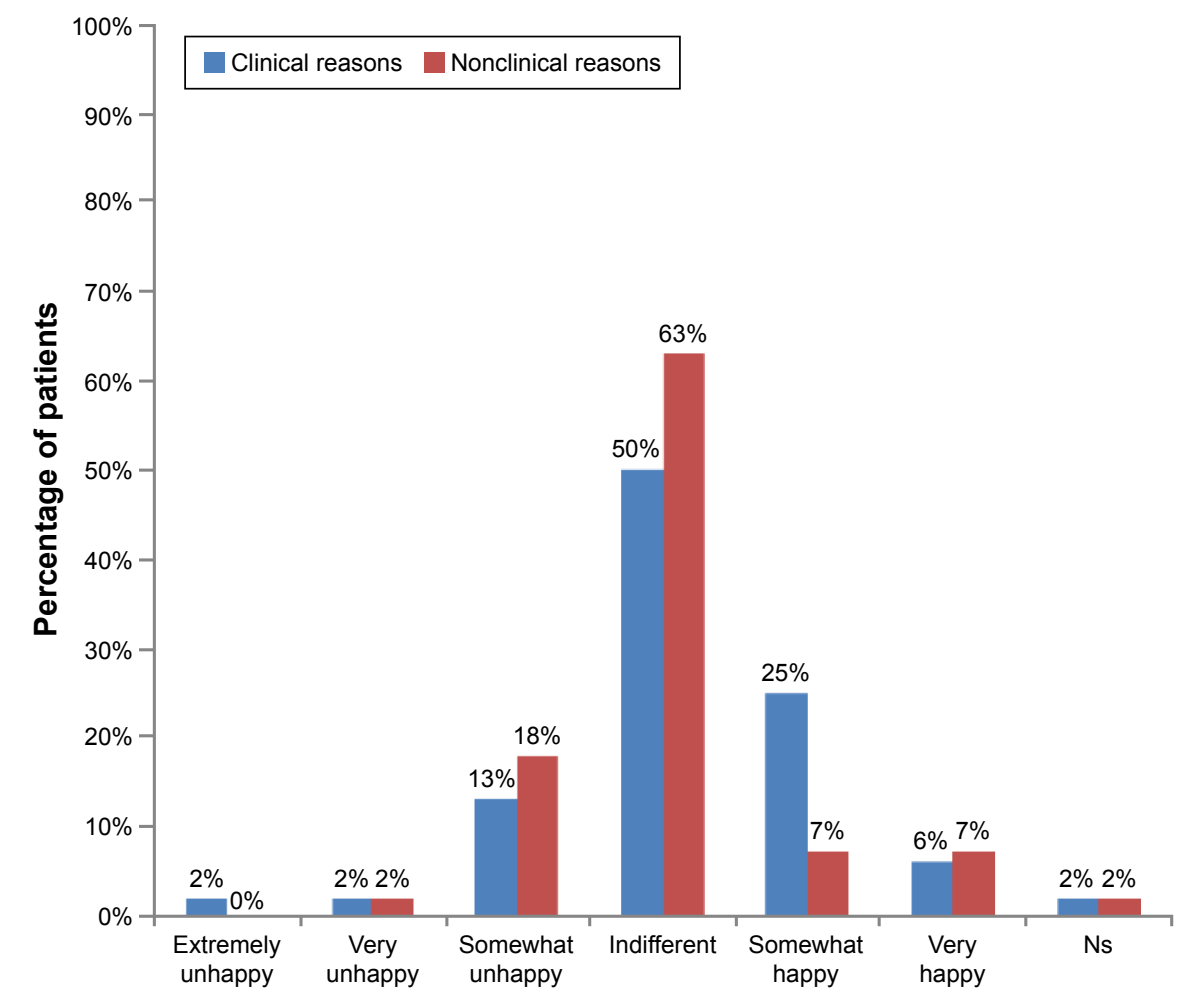

Figure 3 Patient happiness to switch from biooriginator to biosimilar. Abbreviation: Ns, not stated. 
A

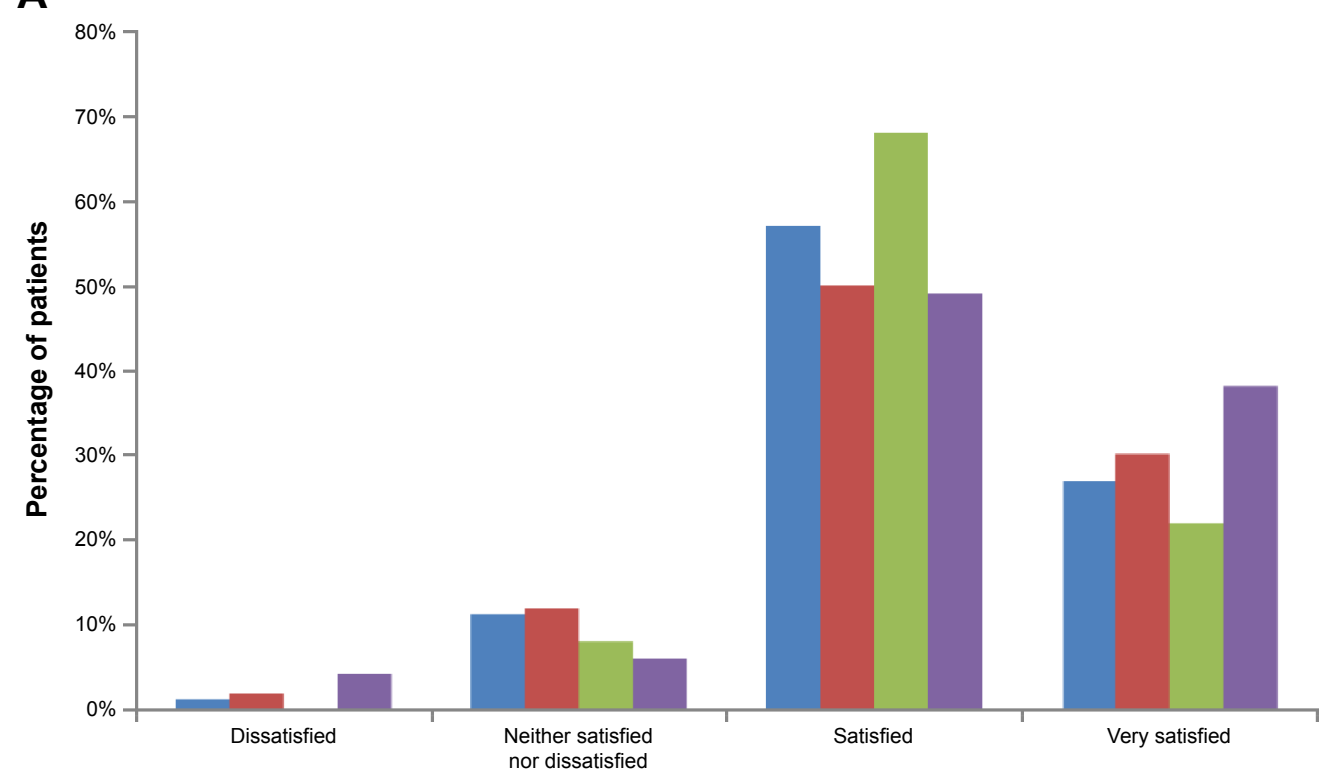

B

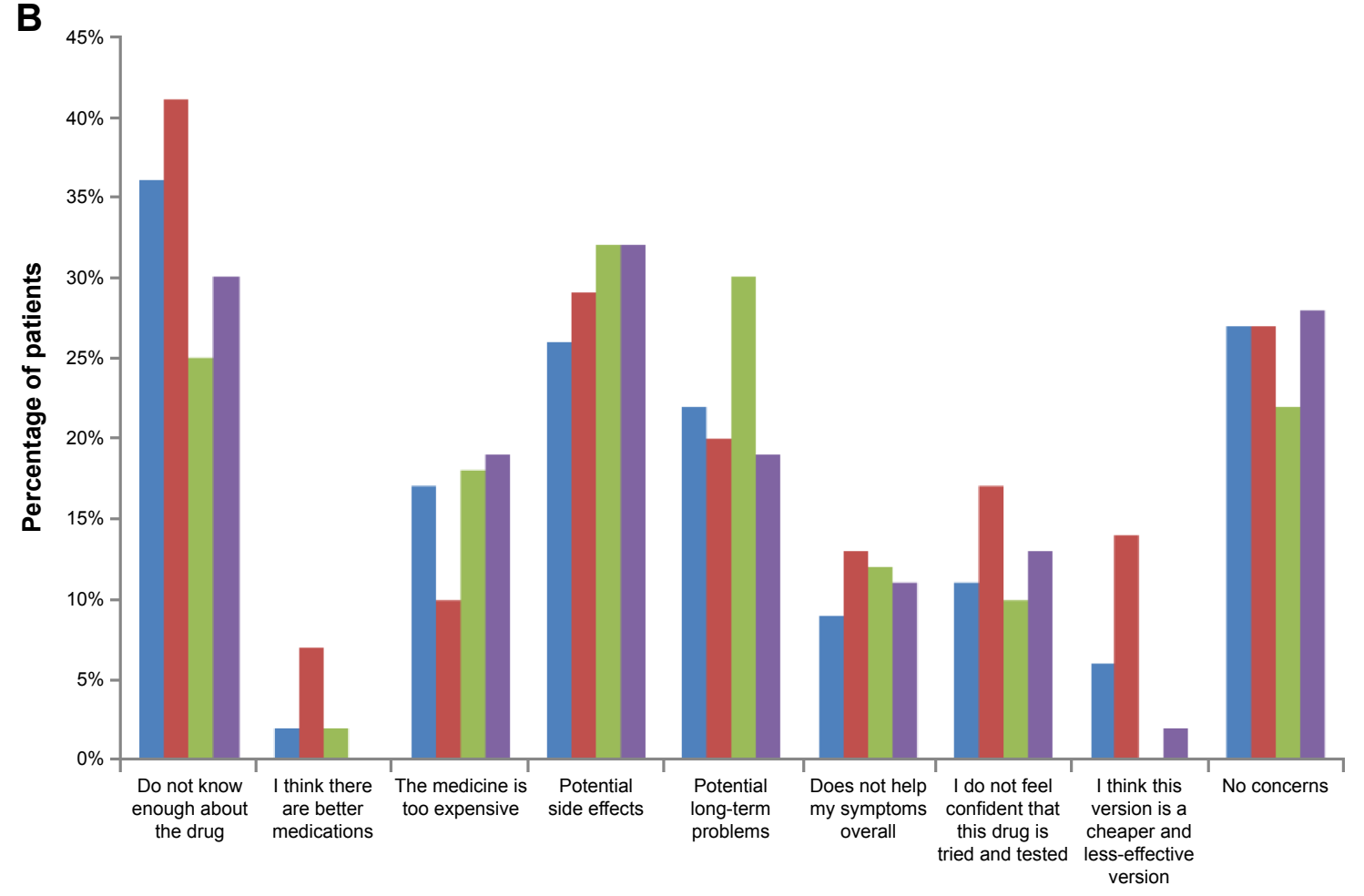

$\square$ BioSN BioSE BioOA BioOB

Figure 4 Patient perceptions of biosimilars.

Notes: (A) Satisfaction with the control of condition by current treatment (does not total $100 \%$ in each group as three patients in BioSN, five patients in BioSE, one patient in BioOA and one patient in BioOB did not respond to this question). (B) Concerns when first prescribed their treatment. BioOA, patient receiving biooriginator who was initiated after February 20I5; BioOB, patient receiving biooriginator who was initiated before January 20I5; BioSN, patient receiving biosimilar who was previously biologic naive; BioSE, patient receiving biosimilar who has an experience of a biooriginator.

being given a cheaper and less-effective version compared to $0-6 \%$ of patients in the other groups.

\section{Discussion}

This article reports current and anticipated prescribing of biosimilars, prescribing preferences and behavior and patient attitudes regarding biosimilars, in the disease areas of RA, AxSpA and PsA.

Reported levels of biosimilar prescribing were low, with fairly modest increases anticipated by physicians over the following 12 months. This may reflect the relatively recent introduction of biosimilars in the field of rheumatology; 
biosimilars for the treatment of chemotherapy-induced neutropenia have $60 \%-80 \%$ market share across the European "big 5" countries. ${ }^{7}$ A report published in March 2016 predicted that biosimilars will result in a highly competitive marketplace over the next 5 years. ${ }^{28}$ There was a marked reluctance on the part of rheumatologists to prescribe biosimilars; the majority indicated they would prefer to prescribe a biooriginator to a biosimilar if there were no guidelines or restrictions for prescribing. Marginally more would prescribe a biosimilar for patients with AxSpA or PsA compared to those with RA; this might reflect the greater range of treatment options currently available for RA than for the other conditions.

More than half of the participating rheumatologists in each of the analysis groups included a wish to gain experience with biosimilars as a reason for prescribing a biosimilar over a biooriginator; this was a reason for $86 \%$ of rheumatologists in the investigative analysis group. However, investigative rheumatologists appeared less concerned about economic factors than those in the conservative or other analysis group. Very little has been published about the reasons that physicians prescribe biosimilars; in a survey of Italian oncologists, $26 \%$ indicated that they would use a biosimilar for the treatment of chemotherapy-induced anemia as they felt this was scientifically supported, while $54 \%$ indicated cost saving as motivation for the treatment choice. ${ }^{29}$ All participating rheumatologists were required to be currently prescribing biosimilars at the first-line therapy; however, a strong preference was indicated for using biooriginators as the first-line therapy should no prescribing restrictions exist, suggesting a possible disconnect between rheumatologists' prescribing behaviors and preferences and some resistance to payer-driven guidelines.

Some reluctance was observed in patients' willingness to accept being prescribed a biosimilar, particularly among patients currently treated with a biooriginator and with no clinically indicated reason for a switch of therapy; $21 \%$ of patients with no clinical reason for the change were somewhat or very unhappy about the switch. As the methodology did not allow for probing to understand the reasons for particular responses, we cannot be certain why some patients were unhappy to be changed from a biooriginator to a biosimilar and others appeared unconcerned. Not knowing enough about the drug was the most common concern of patients when first prescribed their medication; it is likely that this lack of knowledge was critical in the reservations some patients had with regard to biosimilars. It is also likely that the interaction between the rheumatologist and patient will have influenced the patient's viewpoint, either due to the rheumatologist taking the time to ensure that the patient was well informed to reach a shared treatment decision or due to the patient trusting the rheumatologist to make an appropriate treatment decision on their behalf. It is interesting that fewer patients prescribed a biosimilar who had previously received a biooriginator felt that their medication was too expensive compared with the other patient groups, yet more of this group was concerned that they were being given a cheaper and less-effective version than the other groups. It seems likely that these findings reflect patient perceptions of the differing balance of cost and likely effectiveness between biooriginators and biosimilars.

Limited research of patient acceptance of biosimilars has been identified; a survey of patients with type 1 and type 2 diabetes in the USA reported that $66 \%$ of patients indicated that they would "definitely" or "likely" use a less-expensive insulin biosimilar if one were available. ${ }^{30}$ In the current study, the most common concern indicated by patients when prescribed a new treatment was that they did not know enough about the drug, especially for patients prescribed a biosimilar. The fact that, despite this, $27 \%$ of patients receiving a biosimilar had no concerns when first prescribed this treatment might reflect differing physician-patient interactions, with patients whose rheumatologist ensured that they know all they wish to about the treatment having no concerns, while other patients were not well informed by their rheumatologists and indicated this as a concern. These results indicate that patient and physician communication is important and further investigation may be required to determine the extent that additional factors are influencing the conversations. Potential factors, such as volume of patients seen at hospital, care setting and clinician empathy, may affect the time spent on discussing the prescribing of a biosimilar, and such research will help determine how this impacts on patient outcomes. Concern that there are better medications available was low in this study, although a little higher in those receiving biosimilars compared to those on biooriginators. Concern about potential side effects was indicated by around one-quarter to one-third of patients receiving biosimilars and around onethird of those receiving biooriginators. Patients with diabetes expressed concerns about the efficacy and side effects of a biosimilar insulin compared with the biooriginator. ${ }^{30}$ In a survey of patients diagnosed with diseases with biologic treatment options together with members of the general public, $46 \%-51 \%$ of respondents who were aware of biosimilars agreed that biosimilars were effective, with $43 \%-47 \%$ agreeing that they were safe. ${ }^{23}$ 
Some limitations of this study are acknowledged. The study was performed in Germany, which has an advanced health care system and broad access to treatment, which is not universally the case; generalization of the findings beyond Germany warrants caution. ${ }^{31-34}$ The eligibility criteria might have resulted in participating rheumatologists being skewed toward those with a higher workload, and the requirement for rheumatologists to be prescribing biosimilars as the first-line treatment might have resulted in participants who are early adopters of new therapies with different perceptions of biosimilars to rheumatologists who do not prescribe biosimilars. Only patients who presented to a rheumatologist and agreed to participate were included; as a result, the sample might include overrepresentation of patients who consult more frequently and whose characteristics, perceptions, attitudes and concerns differ from the broader patient population. This study did not explore the reasons for patients' medicationrelated concerns and any lack of satisfaction with treatment; a further in-depth qualitative study would provide further insight to patient's perspectives on these issues. Finally, the relatively low sample sizes precluded statistical testing for differences between analysis groups, and this was a crosssectional study rather than a longitudinal study; thus, descriptive data are presented assessing the association between factors rather than an assessment of causality.

It is predicted that by 2020 , biologics will form $28 \%$ of the global pharmaceutical market by value across all therapeutic areas, with biosimilars offering potential savings of $>50$ billion euros across the European big 5 countries and the USA. ${ }^{28}$ Objective patient education about the safety, efficacy and other attributes of all available therapies, including nonbiologics, biooriginators and biosimilars, is critical to allow informed shared decision-making. The findings reported here support a number of publications ${ }^{35,36}$ suggesting that education of physicians and patients, among other stakeholders, about biosimilars is essential to assist informed decision-making and improve acceptance and use of biosimilars where appropriate. ${ }^{20,37,38}$ Further research with rheumatologists and patients to further investigate their understanding, perspectives, and concerns in regard to biooriginators and biosimilars will help ensure that appropriate information is included in any educational initiative.

\section{Key messages}

1. Cost and desire for experience are key factors driving physicians to prescribe biosimilars.

2. Study results demonstrate that there is some reluctance from patients to accept biosimilars.
3. There remains a need to educate patients and rheumatologists who are unsure about biosimilars.

\section{Acknowledgment}

This study was funded by Merck \& Co.

\section{Author contributions}

All authors contributed toward data analysis, drafting and critically revising the paper and agree to be accountable for all aspects of the work.

\section{Disclosure}

CMB and SK are employees of Merck \& Co. and may hold stock and/or options. JW, ES and JP are employees of Adelphi Real World. The authors report no other conflicts of interest in this work.

\section{References}

1. Expert Committee on Biological Standardization [webpage on the Internet]. Guidelines on Evaluation of Similar Biotherapeutic Products (SBPs). Geneva: World Health Organisation; 2009. 1-34. Available from: http://www.who.int/biologicals/areas/biological_therapeutics. Accessed July 29, 2016.

2. Committee for Medicinal Products for Human Use (CHMP). Guideline on similar biological medicinal products containing biotechnologyderived proteins as active substance: quality issues. London; 2012 [cited July 29, 2016]:1-9. Available from: http://www.ema.europa. eu/docs/en_GB/document_library/Scientific_guideline/2014/06/ WC500167838.pdf. Accessed March 2, 2017.

3. US Food and Drug Administration. Quality Considerations in Demonstrating Biosimilarity to a Reference Product: Draft Guidance; 2012. Available from: http://www.fda.gov/downloads/Drugs/Guidance ComplianceRegulatoryInformation/Guidances/UCM291134.pdf. Accessed July 29, 2016.

4. Beck A, Reichert JM. Approval of the first biosimilar antibodies in Europe. $m A$ Abs. 2013;5(5):621-623.

5. McKee $\mathrm{S}$ [webpage on the Internet]. Hospira launches Remicade biosimilar in major EU markets; 2015. Available from: http://www. pharmatimes.com/news/hospira_launches_remicade_biosimilar_in_ major_eu_markets_971052. Accessed August 12, 2016.

6. Hernandez R [webpage on the Internet]. Celltrion Launches Remicade Biosimilar in European Markets. Available from: http://www.biopharminternational.com/celltrion-launches-remicade-biosimilar-europeanmarkets. Accessed August 12, 2016.

7. Generics and Biosimilars Initiative [webpage on the Internet]. Use of biosimilars in Europe differs across countries. GaBOnline; 2014 [cited July 11, 2016]. Available from: http://www.gabionline.net/Reports/ Use-of-biosimilars-in-Europe-differs-across-countries. Accessed July 11, 2016.

8. Niederwieser D, Schmitz S. Biosimilar agents in oncology/haematology: from approval to practice. Eur J Haematol. 2011;86(4):277-288.

9. Regulation Rahmenvertrag. In: German Bundesministerium der Justiz German Social Law Book, 'Aut idem'§ 129;2008. p. section 4 sentence 1. Available from: http://www.gesetze-im-internet.de/ sgb_5/_129.html. Accessed March 2, 2017.

10. GaBI Online - Generics and Biosimilars Initiative [webpage on the Internet]. UK biosimilars uptake lower than in some other EU countries. Available from: http://gabionline.net/Reports/UK-biosimilarsuptake-lower-than-in-some-other-EU-countries. Accessed August 12, 2016. 
11. Rovira J, Espín J, García L, Olry de Labry A. The impact of biosimilars' entry in the EU market. Report prepared for the European Commission (Directorate-General for Enterprise and Industry). Brussels: European Commission; 2011. Available from: http://ec.europa.eu/DocsRoom/ documents/7651/attachments/1/translations/en/renditions/pdf. Accessed October 3, 2016.

12. Weise M, Kurki P, Wolff-Holz E, Bielsky M-C, Schneider CK. Biosimilars: the science of extrapolation. Blood. 2014;124(22):3191-3196.

13. Zelenetz AD, Ahmed I, Braud EL, et al. NCCN Biosimilars White Paper: regulatory, scientific, and patient safety perspectives. $J$ Natl Compr Cancer Netw. 2011;9(suppl 4):S1-S22.

14. Aapro MS. What do prescribers think of biosimilars? Target Oncol. 2012;7(suppl 1):S51-S55.

15. Dolinar RO, Reilly MS. Biosimilars naming, label transparency and authority of choice - survey findings among European physicians. Generics Biosimilars Initiat J. 2014;3(2):58-62.

16. Baji P, Gulácsi L, Lovász BD, et al. Treatment preferences of originator versus biosimilar drugs in Crohn's disease; discrete choice experiment among gastroenterologists. Scand J Gastroenterol. 2016; 51(1):22-27.

17. Baji P, Gulácsi L, Golovics PA, et al. Perceived risks contra benefits of using biosimilar drugs in ulcerative colitis: discrete choice experiment among gastroenterologists. Value Health Reg Issues. 2016;10:85-90.

18. Narayanan S. Relationship between the duration of rheumatology practice experience and likelihood of use and perception towards biosimilars in rheumatoid arthritis arena. Ann Rheum Dis. 2014; 73(suppl 2):624-624.

19. Decision Resources Group [webpage on the Internet]. German Rheumatologists and Gastroenterologists Say They Are Not Under Pressure to Switch Patients on Remicade to Infliximab Biosimilars; 2015. Available from: http://www.prnewswire.com/ news-releases/german-rheumatologists-and-gastroenterologistssay-they-are-not-under-pressure-to-switch-patients-on-remicade-toinfliximab-biosimilars-300145025.html. Accessed March 2, 2017.

20. Nota I, Drossaert CHC, Taal E, Vonkeman HE, van de Laar MA. Patient participation in decisions about disease modifying anti-rheumatic drugs: a cross-sectional survey. BMC Musculoskelet Disord. 2014;15:333.

21. Zangi HA, Ndosi M, Adams J, et al; European League Against Rheumatism (EULAR). EULAR recommendations for patient education for people with inflammatory arthritis. Ann Rheum Dis. 2015;74(6): 954-962.

22. Casey D. Key strategic factors for stakeholders in the current global biosimilar market. Drug Discov Today. 2016;21(2):208-211.

23. Jacobs I, Singh E, Sewell KL, Al-Sabbagh A, Shane LG. Patient attitudes and understanding about biosimilars: an international crosssectional survey. Patient Prefer Adherence. 2016;10:937-948.

24. European Medicine Agency. Summary of the risk management plan (RMP) for Benepali (etanercept). EMA; 2015:1-3. Report No: EMA/783235/2015. Available from: http://www.ema.europa.eu/docs/ en_GB/document_library/EPAR_-_Risk-management-plan_summary/ human/004007/WC500196679.pdf. Accessed August 12, 2016.
25. Generics and Biosimilars Initiative [webpage on the Internet]. Biosimilars of adalimumab; 2014. Available from: http://www.gabionline.net/Biosimilars/General/Biosimilars-of-adalimumab. Accessed August 12, 2016.

26. Pfenex [webpage on the Internet]. Pfenex, Biosimilars, and Better Health; 2015. Available from: http://www.pfenex.com/the-pfenexdifference/. Accessed August 12, 2016.

27. Investor Overview-Investors - EPIRUS Biopharmaceuticals, Inc. Available from: http://ir.epirusbiopharma.com/. Accessed August 12, 2016.

28. Novartis [webpage on the Internet]. Sandoz' biosimilar rituximab regulatory submission accepted by European Medicines Agency. Novartis. Available from: https://www.novartis.com/news/mediareleases/sandoz-biosimilar-rituximab-regulatory-submission-acceptedeuropean-medicines. Accessed August 12, 2016.

29. Anderson P, Benford M, Harris N, Karavali M, Piercy J. Real-world physician and patient behaviour across countries: Disease-Specific Programmes - a means to understand. Curr Med Res Opin. 2008;24(11): 3063-3072.

30. European Pharmaceutical Market Research Association [webpage on the Internet]. European Pharmaceutical Market Research Association Code of Conduct. EphMRA. Available from: http://www.ephmra.org/ Code-of-Conduct-Support. Accessed January 19, 2017.

31. IMS. Delivering on the Potential of Biosimilar Medicines the Role of Functioning Competitive Markets; 2016:1-40. Available from: https:// www.imshealth.com/files/web/IMSH\%20Institute/Healthcare $\% 20$ Briefs/Documents/IMS_Institute_Biosimilar_Brief_March_2016.pdf. Accessed August 12, 2016.

32. Cortinovis D, Beretta G, Piazza E, et al; AIOM Lombardia. Chemotherapy-induced anemia and oncologist perception on treatment: results of a web-based survey. Tumori. 2013;99(1):45-50.

33. Wilkins AR, Venkat MV, Brown AS, et al. Patient perspectives on biosimilar insulin. J Diabetes Sci Technol. 2014;8(1):23-25.

34. Putrik P, Ramiro S, Kvien TK, et al; Working Group 'Equity in access to treatment of rheumatoid arthritis in Europe'. Inequities in access to biologic and synthetic DMARDs across 46 European countries. Ann Rheum Dis. 2014;73(1):198-206.

35. Rak Tkaczuk KH, Jacobs IA. Biosimilars in oncology: from development to clinical practice. Semin Oncol. 2014;41(suppl 3):S3-S12.

36. Moorkens E, Jonker-Exler C, Huys I, Declerck P, Simoens S, Vulto AG. Overcoming barriers to the market access of biosimilars in the European Union: the case of biosimilar monoclonal antibodies. Front Pharmacol. 2016;7:193.

37. Putrik P, Ramiro S, Lie E, et al. Less educated and older patients have reduced access to biologic DMARDs even in a country with highly developed social welfare (Norway): results from Norwegian cohort study NOR-DMARD. Rheumatology (Oxford). 2016;55(7):1217-1224.

38. Putrik P, Ramiro S, Kvien TK, Sokka T, Uhlig T, Boonen A. Variations in criteria regulating treatment with reimbursed biologic DMARDs across European countries. Are differences related to country's wealth? Ann Rheum Dis. 2014;73(11):2010-2021. 


\section{Supplementary materials}

Questions asked of physicians were as follows:

- Table 1 - What percentage of your patients with each condition are currently receiving each product?

- Table 1-What percentage of your patient do you expect will be receiving each product in 12 months' time?

- Figure 1 - Assuming there were no restrictions on your prescribing or guidelines you need to follow, what advanced therapy would you prefer to use first, second and third for each condition?

- Figure 2-Why did you prescribe the biosimilar(s) rather than the originator biologic(s)?

- I wanted to get experience with the new product(s)

- I am convinced of equivalent efficacy compared with biologic originators

- Due to the lower cost

- I believe this to be economic prescribing

- Using biosimilars allows me to make savings which can be used elsewhere

- Due to formulary/hospital guidelines

- Insurance reasons

- Other, specify

- Figure 2 - Once biosimilars are more widely available, how do expect you might use them?

- When a treatment change* is required I will select the biosimilar version of a molecule I would otherwise have prescribed.

- When a treatment change* is required I will select a biosimilar of a different molecule rather than the branded biologic molecule I would otherwise have prescribed.

- In controlled patients currently receiving a branded biologic, I will switch the branded biologic to the biosimilar version.

- In controlled patients currently receiving a branded biologic, I will switch the branded biologic to a biosimilar version of a different molecule.

- Table 2 - Thinking of all the patients who had never before received a biologic originator or biosimilar (ie, biologic/biosimilar naive) for whom you tried to prescribe a biosimilar, what proportion?

- Accepted the switch onto a biosimilar without any reluctance.

- Were reluctant to take a biosimilar but finally accepted as they had no other choice.

- Refused the biosimilar and remained on their existing biologic originator.
- Refused the biosimilar and either switched to an alternative biologic originator or discontinued biologic therapy completely.

- Table 2 - Thinking of all the patients who were receiving an originator biologic who, when they needed a switch of therapy you tried to prescribe a biosimilar, what proportion?

- Accepted the switch onto a biosimilar without any reluctance.

- Were reluctant to take a biosimilar but finally accepted as they had no other choice.

- Refused the biosimilar and remained on their existing biologic originator.

- Refused the biosimilar and either switched to an alternative biologic originator or discontinued biologic therapy completely.

- Table 2-Thinking of all the patients who were receiving an originator biologic who did not clinically need a switch of therapy but you tried to prescribe a biosimilar, what proportion?

- Accepted the switch onto a biosimilar without any reluctance.

- Were reluctant to take a biosimilar but finally accepted as they had no other choice.

- Refused the biosimilar and remained on their existing biologic originator.

- Refused the biosimilar and either switched to an alternative biologic originator or discontinued biologic therapy completely.

Questions asked of patients were as follows:

- Figure 3 - How happy were you to switch from a biooriginator to your current treatment?

- Extremely unhappy

- Very unhappy

- Somewhat unhappy

- Indifferent

- Somewhat happy

- Very happy

- Extremely happy

- Figure 4-Which option best describes your satisfaction with how well your current treatment is controlling your condition/symptoms?

- Very dissatisfied

- Dissatisfied

- Neither satisfied or dissatisfied

- Satisfied

- Very satisfied 
- Figure 4 - What concerns, if any, did/do you have about taking this medication at the times indicated at the top of the columns?

- Don't know enough about the drug

- I think there are better medications

- The medicine is too expensive

- Potential side effects

- Potential long term problems

- Doesn't help my symptoms overall

- I don't feel confident that this drug is tried and tested

- I think this version is a cheaper and less-effective version

o Other

Note: *We are defining a treatment change as either initiation of 1 st biologic or biologic switch.

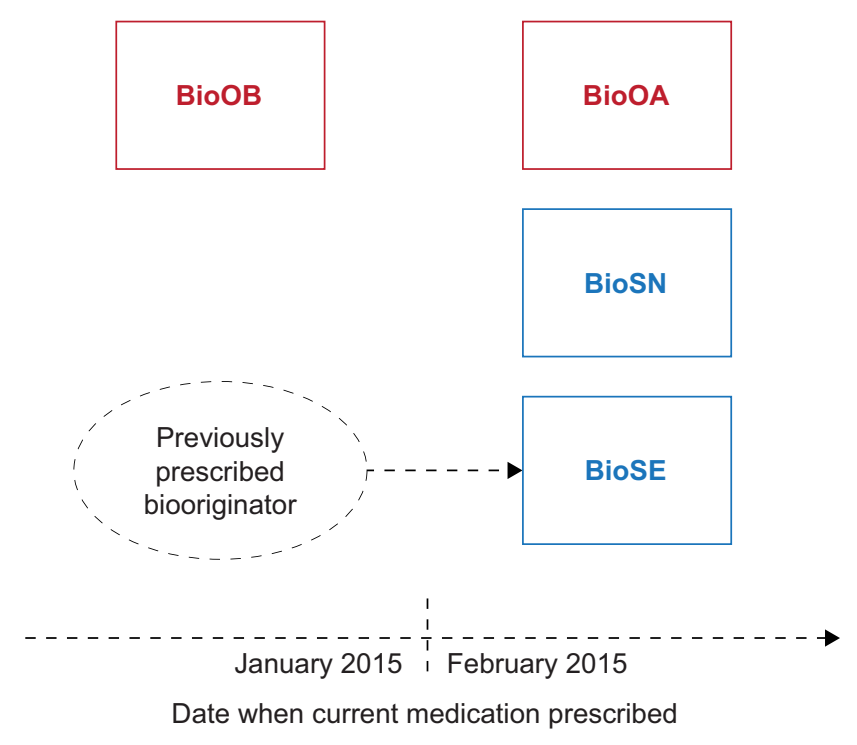

Figure SI Patient analysis groups based on current medication.

Notes: BioOA, patient receiving biooriginator who was initiated after February 2015; BioOB, patient receiving biooriginator who was initiated before January 20I5; BioSN, patient receiving biosimilar who was previously biologic naive; BioSE, patient receiving biosimilar who has an experience of a biooriginator.

\section{Publish your work in this journal}

Patient Preference and Adherence is an international, peer-reviewed, open access journal that focuses on the growing importance of patient preference and adherence throughout the therapeutic continuum. Patient satisfaction, acceptability, quality of life, compliance, persistence and their role in developing new therapeutic modalities and compounds to optimize clinical outcomes for existing disease states are major areas of interest for the journal. This journal has been accepted for indexing on PubMed Central. The manuscript management system is completely online and includes a very quick and fair peer-review system, which is all easy to use. Visit http://www. dovepress.com/testimonials.php to read real quotes from published authors. 